\title{
Article \\ Parametric Study of the Centrifugal Insurance Mechanism in MEMS Safety and Arming Device
}

\author{
Dakui Wang ${ }^{1}$, Wenzhong Lou ${ }^{1}$, Yue Feng ${ }^{1,}$ * and Fufu Wang ${ }^{2}$ \\ 1 National Key Laboratory of Electro-Mechanics Engineering and Control, School of Mechanical-electronic \\ Engineering, Beijing Institute of technology, Beijing100081, China; wangdakui1987@163.com (D.-K.W.); \\ louwz@bit.edu.cn (W.-Z.L.); fengyue@bit.edu.cn (Y.F.) \\ 2 Technology and Engineering Center for Space Utilization, Chinese Academy of Sciences, Beijing 100081, \\ China;wangfufu2004@sina.com \\ * Correspondence: fengyue@bit.edu.cn; Tel.: +86-18310169212
}

\begin{abstract}
MEMS (Micro-electromechanical Systems) becomes important increasingly due to the smarter and smaller fuze used in OICW (Objective Individual Combat Weapon). MEMS Safety and Arming (S\&A) device is employed in different platforms and regions for small caliber projectile. Therefore, it is necessary to make a parametric study of the MEMS S\&A device in different apply environments and explore the main sensitive factors of the MEMS S\&A device to provide reference for designs. In this paper, based on the MEMS S\&A device designed by our term, theory and finite element models are established, and the centrifugal insurance mechanism of the MEMS S\&A device is parametric studied under the different speeds, temperature and thickness of the model by nonlinear dynamic method. By comparing the experimental and predicted results, the established FEM model is verified, and the conclusion is that the temperature and the centrifugal force are the main sensitive factors in the centrifugal insurance mechanism. In summary, we can suggest that the application environment, which the MEMS S\&A device is suitable for, is the temperature equal to or slightly greater than normal temperature and the rotating speed higher than $35000 \mathrm{r} / \mathrm{min}$ of small caliber projectile.
\end{abstract}

Keywords: MEMS S\&A device; centrifugal insurance mechanism; nonlinear dynamic method; parametric study

\section{Introduction}

The fuze S\&A device is an important part of ammunition. The S\&A device is intended as a key component in ensuring fuze safety in the service processing and launching process, and then to assure arming reliability under certain incentives after ammunition launching [1-4]. With the development of the ammunition technology, the developing trends of the fuze technology should be miniaturization, smart, high reliability and low cost [5-7], so MEMS becomes important increasingly [8-9]. Traditional S\&A device can accomplish the safety and arming functions of fuze, but it is not available for small-caliber ammunition because of its large size, many parts and poor anti-overload capability [10-13]. MEMS S\&A device has small size, light weight and good anti-overload capability, it makes more space for conventional fuze to accommodate the multi-sensor detection circuit and the main power supply module, finally the precision and lethality of ammunition is improved [14-17]. The miniaturization of S\&A device takes priority over other tasks [18-21]. Since 1990s, the superiority and approaches of MEMS fuze have been introduced [22-25]. The most common MEMS S\&A devices are shown in Figure 1. In recent years, the U.S. fuze annual conferences reported that the performance of on-chip-based S\&A device is tested using the missile warhead at present [26-30], and the development trend of fuze technology is on-chip integration of machinery, electronics and pyrotechnics in the future. 


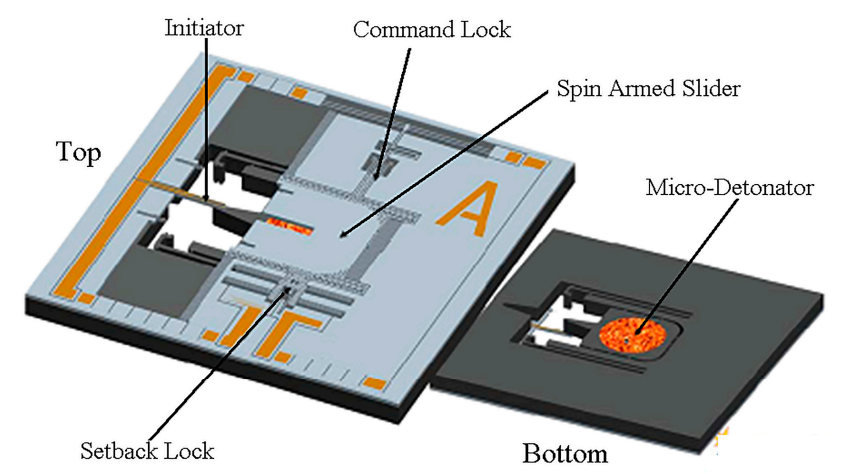

Figure 1. The common MEMS S\&A device.

On this basis, our term developed a MEMS S\&A device used in small-caliber ammunition innovatively, and the concrete structure as shown in Figure 2 [31-33]. The size of the device is $\Phi 14 \times 15$ $\mathrm{mm}$ (except detonating tube, electric detonator and electric thruster). In the launching state, MEMS S\&A device withstand the setback overload and centrifugal force, and the centrifugal insurance mechanism (13) releases the explosion-proof slider. Because of the launch state lasts a long time during centrifugation environment, centrifugal insurance mechanism (13) can maintain the arming state. When ammunition flies a certain distance, electric thruster (4) works and the explosion-proof slider (12) in the long-distance safety insurance mechanism is released. The explosion-proof slider (12) overcomes the tension of MEMS spring (6) and moves quickly, and the latching mechanism (11) works, the fuze enters the state of waiting arming. The role of the centrifugal insurance mechanism is to ensure the safety in handling transportation and storage, and reliable firing with the launch overload. Because the MEMS S\&A device is used in different platforms and different regions of small caliber projectile, it is necessary to study the MEMS S\&A device and explore the main sensitive factors of the MEMS S\&A device. Then, according to the main sensitive factors of the MEMS S\&A device, the recommendations of the apply experiment and optimal design for the MEMS S\&A device can be put forward.

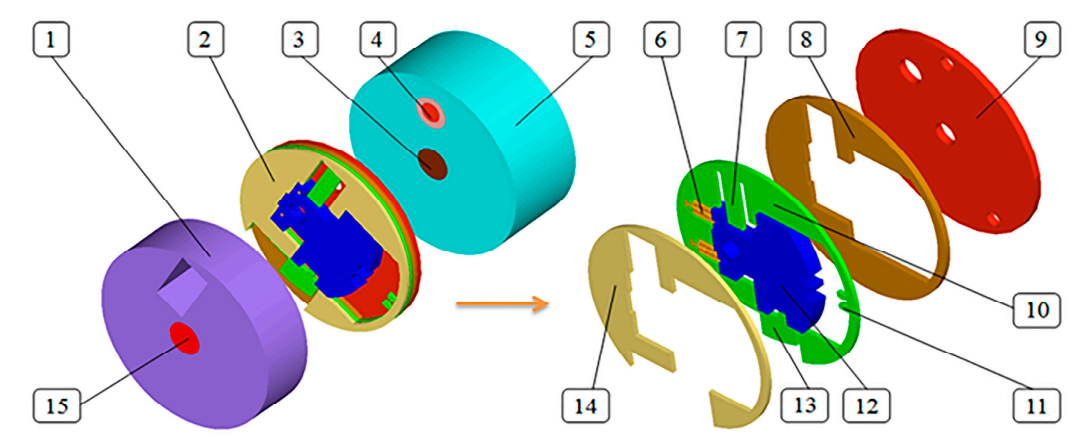

Figure 2. Designed MEMS S\&A device. 1-Detonating tube base; 2-Safty and arming module; 3-Electric detonator; 4-Electric thruster; 5-Electric detonator base; 6-MEMS spring; 7-Latching reed ; 8-Top plate ; 9-Cover plate ; 10-Middle plate ; 11-Latching mechanism; 12-Explosion-proof slider ; 13-Centrifugal insurance mechanism ; 14-Bottom plate ; 15-Detonating tube.

A few works have been carried out for detailed analysis of the MEMS S\&A device. This paper aims to understand the main sensitive factors of the centrifugal insurance mechanism in MEMS S\&A module. First, the simulation models for MEMS S\&A module are established, which the influence of the temperature, the setback overload, the centrifugal force and the thickness of the model are studied based on the established models. Finally, the experimental results are presented, and the corresponding simulation models are verified quantitatively. The research can provide fundamental knowledge for optimizing model parameters. 


\section{Simulation}

\subsection{Materials}

In this paper, the centrifugal insurance mechanism of the MEMS S\&A device (Figure 2) is parametric studied, considering its overall characteristics and weak links in the multi physical field. The ANSYS/LS-DYNA explicit dynamic analysis software is used for simulating the model, wherein thereof the element type is MAT_PLASTIC_KINEMATIC. The material of the centrifugal insurance mechanism is beryllium bronze, and the mechanical parameters of the material are shown in Table 1.

Table 1. The mechanical parameters of the beryllium bronze

\begin{tabular}{cc}
\hline Parameters & Value \\
\hline Density $\left(\mathrm{kg} / \mathrm{m}^{3}\right)$ & $8.3 \times 10^{3}$ \\
Young's modulus $(\mathrm{GPa})$ & 133 \\
Poisson's ratio & 0.33 \\
Yield strength $(\mathrm{GPa})$ & 1.2 \\
Tangent modulus $(\mathrm{GPa})$ & 35 \\
\hline
\end{tabular}

\subsection{Methods}

A three-dimensional model and simplified finite element model of the MEMS S\&A module are established respectively, as shown in Figure 3 and Figure 4 . The size of the MEMS S\&A module is $\Phi 12 \times 0.3 \mathrm{~mm}$.

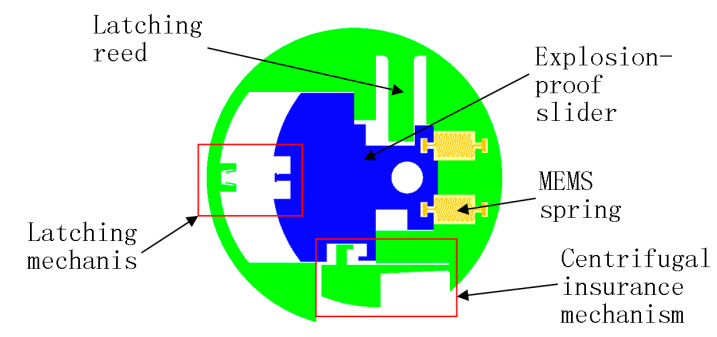

(a)

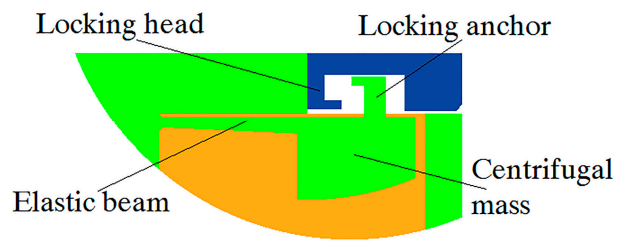

(b)

Figure 3. (a) Designed MEMS S\&A module; (b) The centrifugal insurance mechanism.

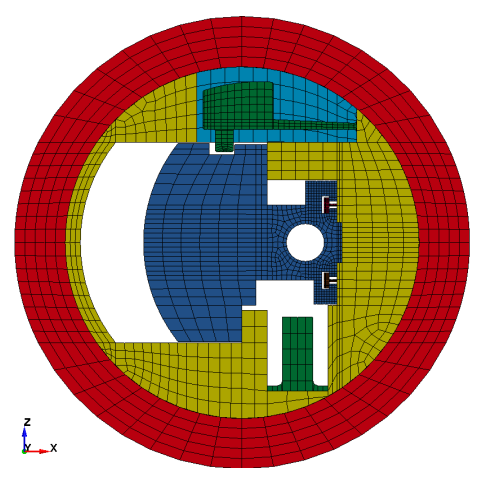

Figure 4. Simplified finite element model of MEMS S\&A module.

For small caliber projectile, it has the highest centrifugal force and setback overload. Nonlinear dynamic mechanics simulation is built using ANSYS/LS-DYNA, under loading the centrifugal force and setback overload (shown in Figure 5) at the temperatures of $25^{\circ} \mathrm{C}, 50^{\circ} \mathrm{C}$ and $-40^{\circ} \mathrm{C}$, respectively. The simulation results are shown in Figure 6 and Table 2. 


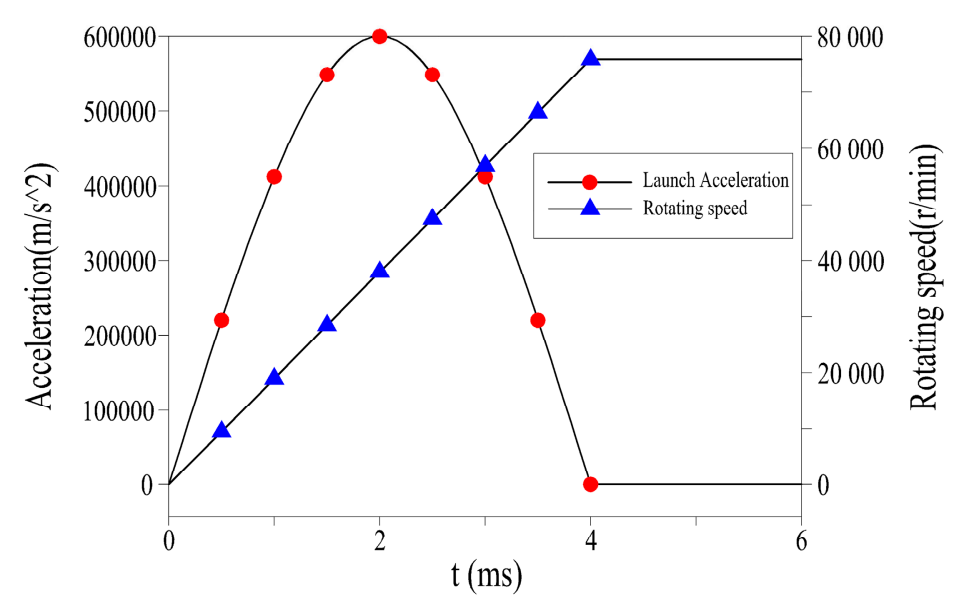

Figure 5. The centrifugal and overload force curve.

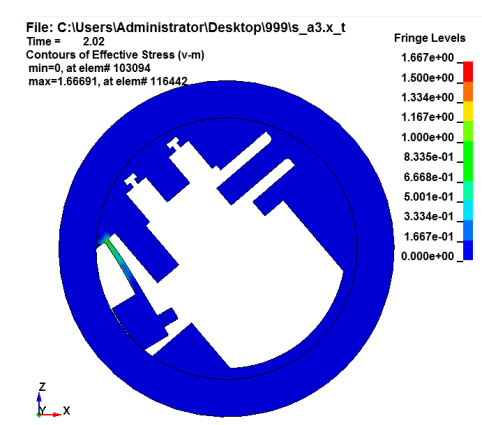

(1)

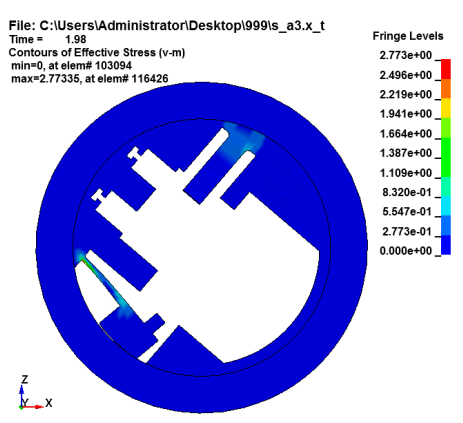

(2)

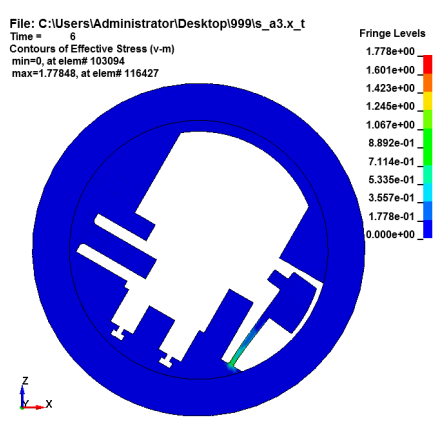

(3)

Figure 6. The simulation results of the MEMS S\&A module under the different loads and the temperature. (1) Loading the centrifugal force $\left(25^{\circ} \mathrm{C}\right) ;(2)$ Loading the centrifugal force and setback overload $\left(25^{\circ} \mathrm{C}\right) ;(3)$ Loading the centrifugal force $\left(-40^{\circ} \mathrm{C}\right)$.

Table 2. Simulation results under different loads and temperatures.

\begin{tabular}{cccc}
\hline Load & $\begin{array}{c}\text { Initial motion time of } \\
\text { centrifugal insurance } \\
\text { mechanism }(\mathbf{m s})\end{array}$ & $\begin{array}{c}\text { Arming time } \\
(\mathbf{m s})\end{array}$ & $\begin{array}{c}\text { Arming process } \\
\text { duration }(\mathbf{m s})\end{array}$ \\
\hline $\begin{array}{c}\text { Centrifugal force }\left(25^{\circ} \mathrm{C}\right) \\
\text { Centrifugalforce and setback }\end{array}$ & 1.57 & 2.02 & 0.45 \\
$\begin{array}{c}\text { overload }\left(25^{\circ} \mathrm{C}\right) \\
\text { Centrifugal force }\left(50^{\circ} \mathrm{C}\right)\end{array}$ & 1.56 & 1.98 & 0.42 \\
Centrifugal force $\left(-40^{\circ} \mathrm{C}\right)$ & 1.58 & 2.01 & 0.43 \\
\hline
\end{tabular}

According to the above simulation results, we can obtain that the initial motion time of centrifugal insurance mechanism under loading the centrifugal force is $1.57 \mathrm{~ms}$, and the initial motion time very close of centrifugal insurance mechanism under loading the centrifugal force and setback overload is $1.56 \mathrm{~ms}$; The arming time of centrifugal insurance mechanism under loading the centrifugal force is $2.02 \mathrm{~ms}$, which is more $0.04 \mathrm{~ms}$ than that under loading the centrifugal force and setback overload, the difference is very small. In addition, it can be seen from the stress cloud that the stress of centrifugal insurance mechanism under loading the centrifugal force and setback overload is greater than that under loading the centrifugal force. So we can conclude that the setback overload can obviously increase the stress value of the material, but has almost no effect on the arming time of centrifugal insurance mechanism. The simulation results of different temperatures can be seen that centrifugal insurance mechanism cannot be effectively armed at low temperature $\left(-40^{\circ} \mathrm{C}\right)$, the reason that the low temperature affects the material properties of the structure, instead, 
the centrifugal insurance mechanism can effectively be arming at a little higher temperature $\left(50^{\circ} \mathrm{C}\right)$ than the normal temperature.

Therefore, in summary, the temperature is one of the main sensitive factors of the centrifugal insurance mechanism.

Furthermore, when loading the different centrifugal forces (the rotating speeds at the range of32000 r/min and $95000 \mathrm{r} / \mathrm{min}$ ) to the MEMS S\&A module, the simulation results are shown in Figure7, Figure8 and Table 3.

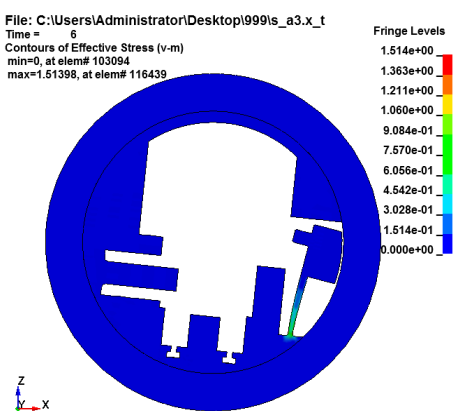

(1)

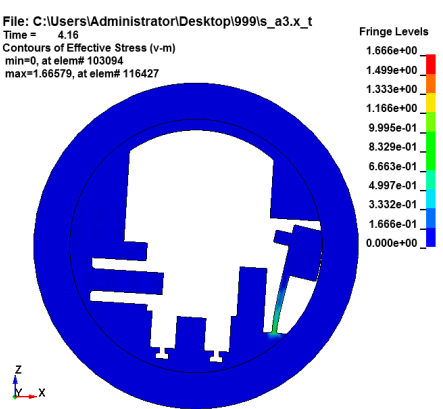

(2)

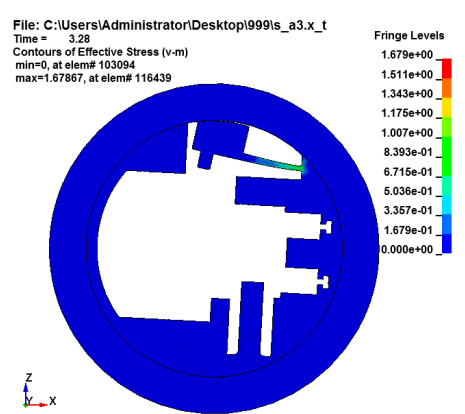

(3)

Figure 7. The simulation results of loading the different rotating speeds to the MEMS S\&A module. (1) 34000r/min;(2)35000r/min;(3) 45000r/min.

Table 3. Simulation results under different rotating speeds.

\begin{tabular}{cccc}
\hline $\begin{array}{c}\text { Rotating speed } \\
(\mathbf{r} / \mathbf{m i n})\end{array}$ & $\begin{array}{c}\text { Initial motion time of centrifugal } \\
\text { insurance mechanism }(\mathbf{m s})\end{array}$ & $\begin{array}{c}\text { Arming time } \\
(\mathbf{m s})\end{array}$ & $\begin{array}{c}\text { Arming process } \\
\text { duration }(\mathbf{m s})\end{array}$ \\
\hline 32000 & 3.58 & Failed & Failed \\
33000 & 3.46 & Failed & Failed \\
34000 & 3.36 & Failed & Failed \\
35000 & 3.29 & 4.16 & 0.87 \\
45000 & 2.60 & 3.28 & 0.68 \\
55000 & 2.13 & 2.70 & 0.57 \\
65000 & 1.77 & 2.26 & 0.49 \\
75000 & 1.57 & 2.02 & 0.45 \\
85000 & 1.43 & 1.85 & 0.42 \\
95000 & 1.29 & 1.69 & 0.40 \\
\hline
\end{tabular}

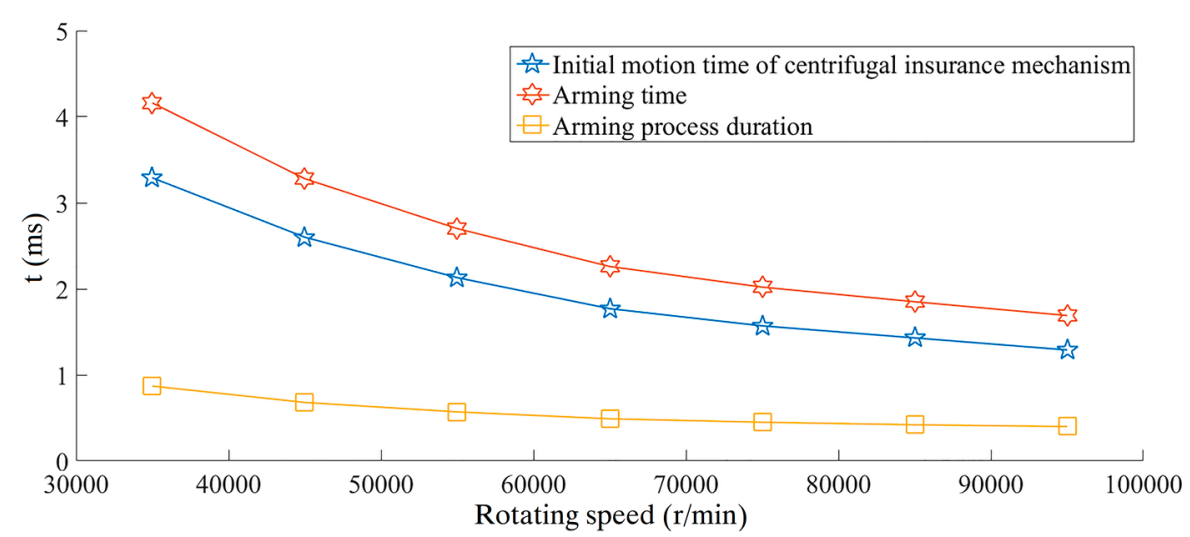

Figure 8. Fitting curve of the simulation data.

As can be seen from table 3, when the rotating speed reaches 35000r/min, the centrifugal insurance mechanism can be effectively armed. At the same time, with the increase of rotating speed, the initial motion time of centrifugal insurance mechanism, the arming time and the arming process duration, all tend to be decreased. As can be seen from Figure 8, with the increase of rotating 
speed, the decreasing trend of the initial motion time of centrifugal insurance mechanism, arming time and arming process duration are decreased gradually.

It is undoubtedly that the rotating speed is another main sensitive factor of the centrifugal insurance mechanism.

From the above analysis, it is shown that the critical load value of the centrifugal insurance mechanism which can be removed from the insurance is $35000 \mathrm{r} / \mathrm{min}$. Loading the constant centrifugal force $(35000 \mathrm{r} / \mathrm{min})$, at the same time, reestablishing the different thickness of centrifugal insurance mechanism(between $0.24 \mathrm{~mm}$ and $0.34 \mathrm{~mm}$ ), and the results of final state are demonstrated in Figure 9 and Table 4.

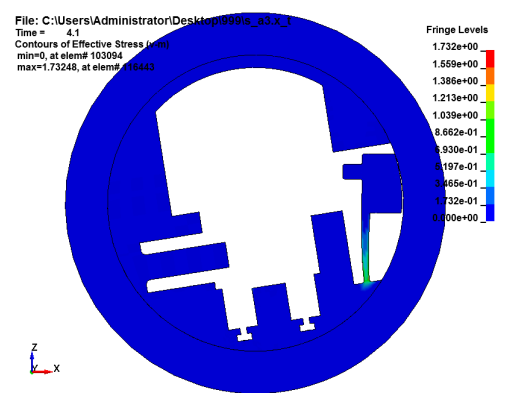

(1)

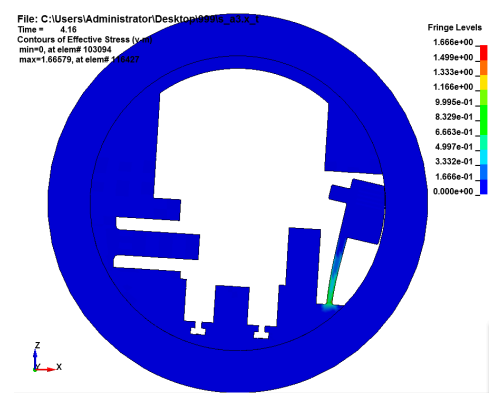

(2)

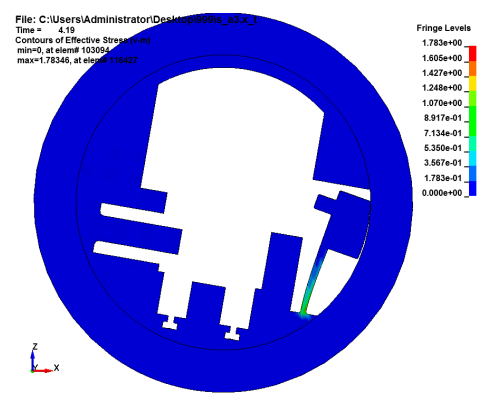

(3)

Figure 9. Simulation results of different thickness of the centrifugal insurance mechanism under the constant centrifugal force. (1) $0.24 \mathrm{~mm}$; (2) $0.30 \mathrm{~mm}$; (3) $0.34 \mathrm{~mm}$.

Table 4. Simulation results under different thickness of the model.

\begin{tabular}{cccc}
\hline Thickness (mm) & $\begin{array}{c}\text { Initial motion time of centrifugal } \\
\text { insurance mechanism }(\mathbf{m s})\end{array}$ & Arming time (ms) & $\begin{array}{c}\text { Arming process } \\
\text { duration }(\mathbf{m s})\end{array}$ \\
\hline 0.24 & 2.22 & 4.10 & 0.88 \\
0.26 & 2.25 & 4.11 & 0.86 \\
0.28 & 3.25 & 4.12 & 0.87 \\
0.30 & 3.29 & 4.16 & 0.87 \\
0.32 & 3.30 & 4.18 & 0.88 \\
0.34 & 3.33 & 4.19 & 0.86 \\
\hline
\end{tabular}

It can be obtained from the simulation results above, when the centrifugal insurance mechanism takes different thickness, it can effectively be arming at the same centrifugal force, so it can be argued that the thickness has no effect on the arming time of centrifugal insurance mechanism.

To verify the above statement, the centrifugal insurance mechanism is calculated theoretically. The deflection of the centrifugal insurance mechanism is analyzed by the beam deflection curve equation in material mechanics, as shown in figure 10.

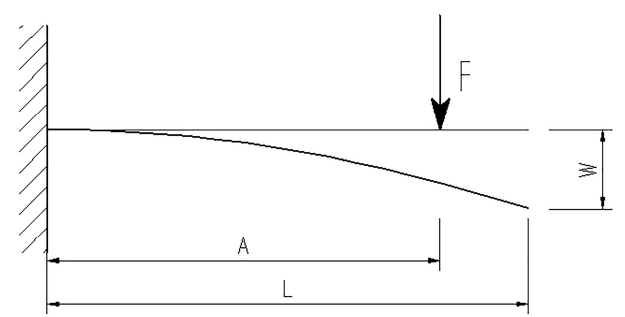

Figure 10. Schematic diagram of theoretical analysis.

The deflection equation of the centrifugal insurance mechanism is 


$$
W=-\frac{F x^{2}}{6 E I}(3 A-x) .
$$

When $\mathrm{x}=\mathrm{L}$, the deflection value at $\mathrm{L}$ is

$$
W_{L}=-\frac{F x^{2}}{6 E I}(3 A-L)
$$

Then, centrifugal force $\mathrm{F}$ is

$$
F=m A \omega^{2}=\rho v A \omega^{2}=\rho s_{0} h A \omega^{2} .
$$

Wherein, $\rho$ is the material density of the centrifugal insurance mechanism, $s_{0}$ is surface area of the centrifugal insurance mechanism, $h$ is the thickness of the centrifugal insurance mechanism , $A$ is the rotation radius of centroid in the centrifugal insurance mechanism and $\omega$ is the rotating speed.

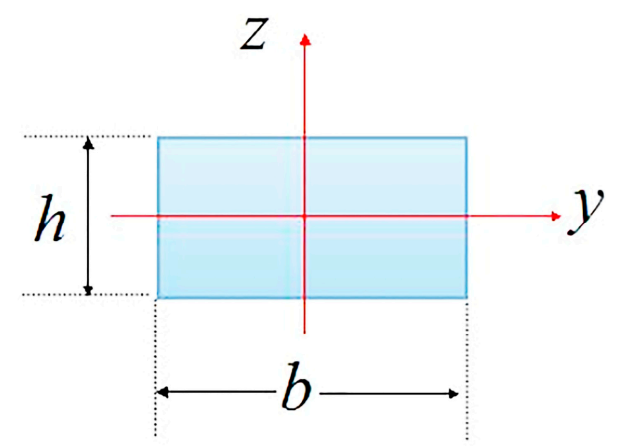

Figure 11. Beam section and corresponding coordinates.

The section of beam as shown in Figure 11, so the moment of inertia for centrifugal insurance mechanism on the $\mathrm{Z}$ axis is

$$
I_{z}=\frac{h b^{3}}{12} .
$$

Taking the cross section of the root for the centrifugal insurance mechanism as the research object, thus, we can get

$$
W_{L}=-\frac{\rho s_{0} h r \omega^{2} L^{2}}{6 E \frac{h b^{2}}{12}}(3 A-L)=-\frac{2 \rho s_{0} r \omega^{2} L^{2}}{E b^{3}}(3 A-L) .
$$

Wherein, $b$ is the width of the beam section in the centrifugal insurance mechanism.

According to the above formula, the formula does not contain the parameter of $h$, therefore the thickness has nothing to do with the motion of the centrifugal insurance mechanism, which is consistent with the simulation results.

\section{Experiment}

Using nickel-based material and UV-LIGA processing technology to manufacture the MEMS spring, beryllium bronze material and low-speed wire-cutting electrical discharge processing technology are used to manufacture the other parts of MEMS S\&A module that we have designed. The detailed structure of MEMS S\&A module is shown in Figure 12. 


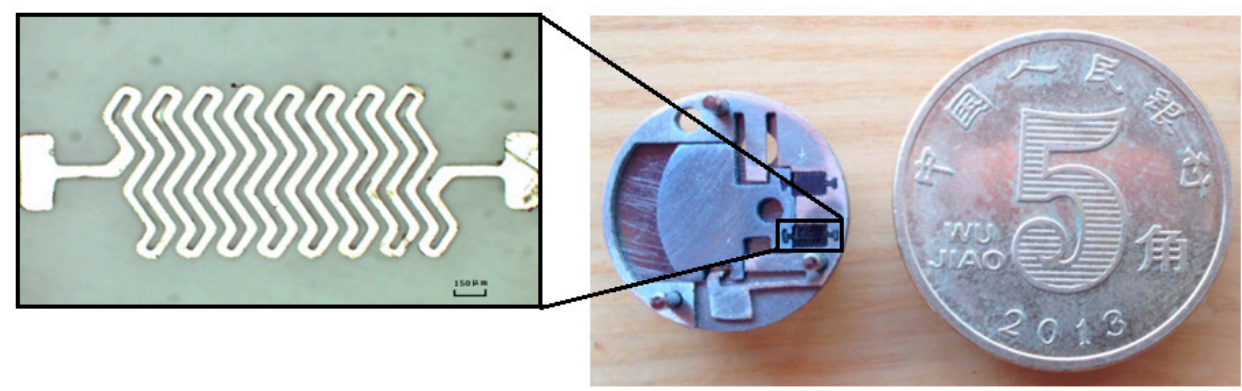

Figure 12. Detailed structure of MEMS S\&A module.

Due to the limitations of the experiment conditions, we just carry out the centrifugal experiments on the MEMS S\&A device. The experimental equipment is shown in Figure 13. Loading different rotating speeds (between $32000 \mathrm{r} / \mathrm{min}$ and $40000 \mathrm{r} / \mathrm{min}$ ) to the MEMS S\&A device, the experiments are carried out and four groups of experiments are operated.
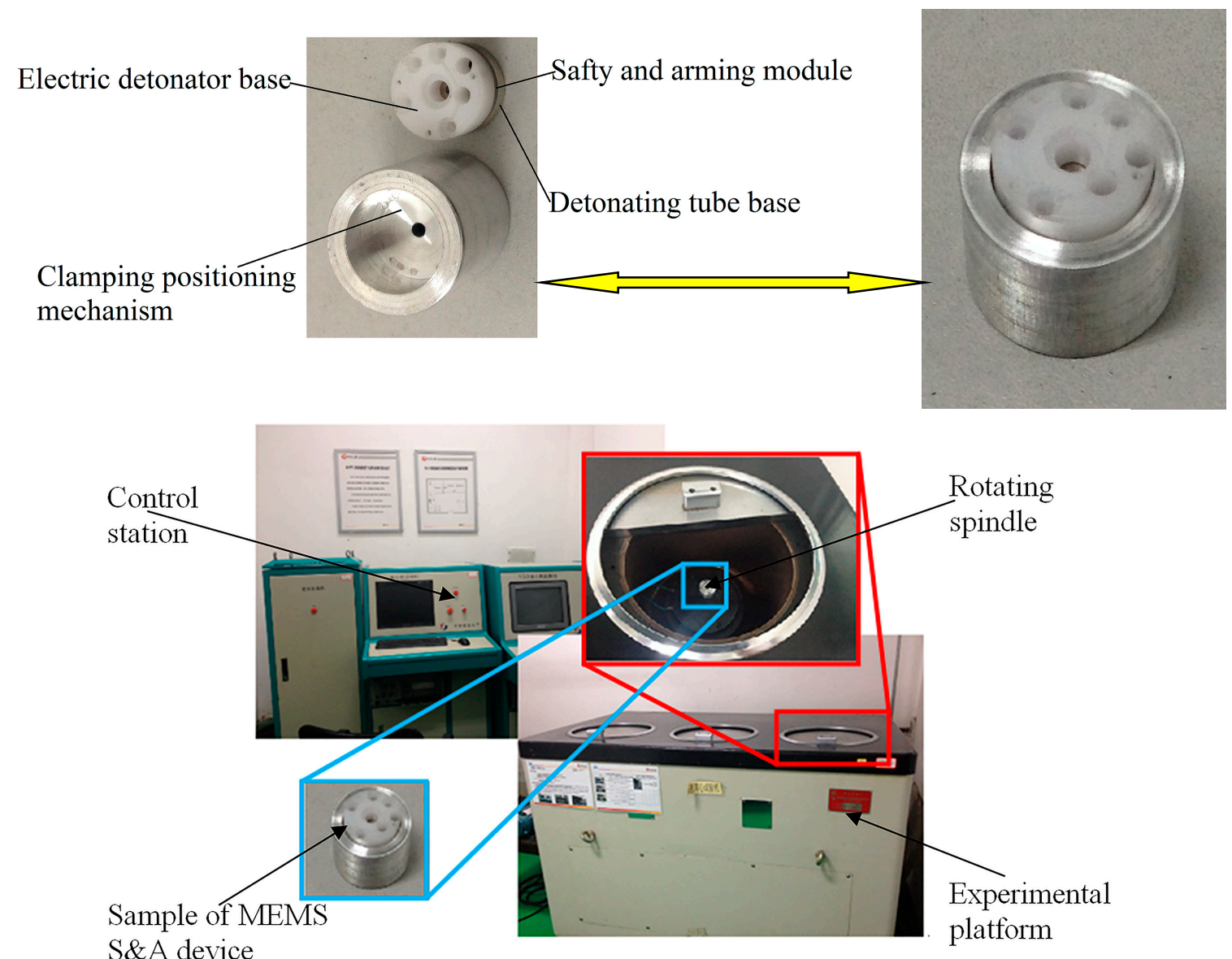

Figure 13. The experimental equipment.

Through the experiment, we can get that the experiment results under different rotating speeds can be expressed as the form of the Table 5 , and the experimental status of centrifugal insurance mechanism which can effectively arming is shown in Figure 14. 


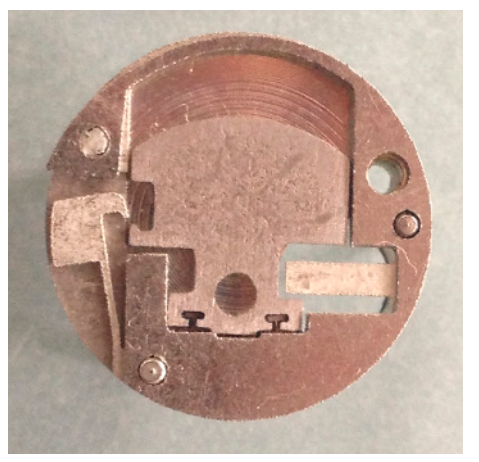

Figure 14. The arming status of centrifugal insurance mechanism.

Table 5. The experiment results under different rotating speeds.

\begin{tabular}{cccccc}
\hline $\begin{array}{c}\text { Group } \\
\text { number }\end{array}$ & $\begin{array}{c}\text { Rotating speed } \\
(\mathbf{r} / \text { min) }\end{array}$ & Arming status & $\begin{array}{c}\text { Group } \\
\text { number }\end{array}$ & $\begin{array}{c}\text { Rotating speed } \\
(\mathbf{r} / \mathbf{m i n})\end{array}$ & Arming status \\
\hline \multirow{4}{*}{1} & 33000 & no & & 33000 & no \\
& 34000 & no & & 34000 & no \\
& 35000 & no & 2 & 35000 & no \\
& 36000 & yes & & 36000 & no \\
& 37000 & yes & & 37000 & yes \\
\hline 40000 & yes & no & & 30000 & yes \\
\hline \multirow{3}{*}{3} & 33000 & no & & 34000 & no \\
& 34000 & yes & 4 & 35000 & no \\
& 35000 & yes & & 36000 & yes \\
& 36000 & yes & & 37000 & yes \\
& 37000 & yes & 40000 & yes \\
\hline
\end{tabular}

According to the table 5, we can get the minimum rotating speed of arming for Centrifugal insurance mechanism about each experiment, and the average value of the minimum rotating speeds is $3600 \mathrm{r} / \mathrm{min}$. Comparing the experiment result with the simulation result $(3500 \mathrm{r} / \mathrm{min})$, we can know that the experiment result is slightly bigger than the simulation result, the reason is that the friction and damping are ignored in the simulation. The experiment results and simulation results are basically consistent. Thus, it can be proved that the simulation result is reliable.

\section{Conclusions}

In this paper, based on the MEMS S\&A device designed by our term, the main sensitive factors of the centrifugal insurance mechanism in the MEMS S\&A device are explored by parametric studies. Theory model is established and analysis. Finite element models are used to study the influence of the temperature, the setback overload, the centrifugal force and the thickness of the model. At the same time, the centrifugal insurance mechanism under different speeds is parametric studied by experiment. Through the above simulation and experiment results, it can be obtained the following conclusions.

1) The setback overload has a little effect on the arming time of the centrifugal insurance mechanism, but it has a great effect on the stress of the elastic beam. Furthermore, temperature environment can affect the arming time of the centrifugal insurance mechanism, and the effect of low temperature on the arming time of the centrifugal insurance mechanism is bigger than that of high temperature through the Table 2.

2) As can be seen from table 3, when the rotating speed reaches $35000 \mathrm{r} / \mathrm{min}$, the centrifugal insurance mechanism can effectively be armed. At the same time, with the increase of rotating speed, the initial motion time of centrifugal insurance mechanism, the arming time and the arming process duration, all tends to be decreased. With the increase of rotating speed, the decreasing trend 
of the initial motion time of centrifugal insurance mechanism, arming time and arming process duration decreases gradually based on the results, as shown in Figure 8.

3) Comparing the experiment result with the simulation result, it can be obtained that the experiment result and the simulation result are basically consistent; it can be proved that the results are reliable and the centrifugal force is one of the main sensitive factors of the centrifugal insurance mechanism.

4) Under the critical centrifugal force, the centrifugal insurance mechanism can normally remove the insurance when the model has different thicknessby the Table 4. Compared with theoretical analysis, then, it is shown that the thickness has a little effect on the model.

In summary, the temperature and the centrifugal force are the main sensitive factors of the centrifugal insurance mechanism in the MEMS S\&A device.

Acknowledgments: The research is supported by the State Key Laboratory of Mechatronics Engineering and Control and sponsored by National Project (No. Z092014B001 and No. B3320132011).

Author Contributions: W.-Z.L. conceived the problem and designed the solution; F.-F.W. and Y.F. designed the experiments; C.-S.C. performed the experiments; F.-F.W. and D.-K.W. analyzed the data; D.-K.W. wrote the paper.

Conflicts of Interest: The authors declare no conflict of interest.

\section{References}

1. Onkar, K.; Sujay, G.; Ankush, H. Safety and Arming Mechanism (SAM) for MortarFuze.International Journal for Scientific Research \& Development. 2015, 3,637-639.

2. Li, X.; Zhao, Y.; Hu, T. Design of a high-speed electrothermal linear micromotor for microelectromechanical systems safety-and-arming devices. Let Micro \& Nano Letters. 2016, 11, 692 -696.

3. Shaeffer, D.K. MEMS inertial sensors: a tutorial overview. IEEE Commun. Mag. 2013, 51,100-109.

4. Liu, F.Y.; Lou, W.Z.; Wang, F.F. Parametric research of MEMS safety and arming system. Appl.Sci. Eng. 2014, 17, 25-30.

5. Wang, Y.; Lou, W.Z.; Feng, Y. High impact dynamic simulation of planar S-form micro-spring. Key Eng. Mater.2013, 562, 1107-1110.

6. Jiang, X.H.; Yin, Q.; Tian, Y. Study on MEMS initiators. Initiat Pyrotech. 2009, 6, 11-13.

7. Pezous, H.; Rossi, C.; Sanchez, M. Fabrication, assembly and tests of a MEMS-based safe, arm and fire device. Journal of Physics and Chemistry of Solids. 2010, 71, 75-79.

8. Xu, W.; Yang, J.; Xie, G.F. Design and Fabrication of a Slanted-Beam MEMS Accelerometer. Micromachines. 2017, 8, 77; doi:10.3390/mi8030077.

9. Wang, X.D.; Mao, S.C.; Zhang, J.F. MEMS Device for Quantitative in Situ Mechanical Testing in Electron Microscope. Micromachines. 2017, 8, 31; doi:10.3390/mi8020031.

10. Wang, S.W.; Hao, Y.P.; Zhang, D.Z. The comprehensive analysis of MEMS-based fuze safety and arming device. Detect Control. 2006, 28, 55-58.

11. Hélène, P.; Carole, R.; Marjorie, S. Integration of MEMS based safe arm and fire device. Sensors \& Actuators A Physical. 2010, 159,157-167.

12. Feng, P.Z.; Zhu, J.N.; Wu, Z.L. Analysis of US typical MEMS fuze safety \& arming device. Detect Control. 2007, 29, 26-30.

13. Pezous, H.; Rossi, C. ; Sanchez, M. Fabrication, assembly and tests of a MEMS-based safe, arm and fire device. Phys Chem Solids. 2010, 71, 75-79.

14. Robinson, C.H. Ultra-miniature, monolithic, mechanical safety-and- arming (S\&A) device for projected munitions. USP: 6064013, 2001.

15. Li, X.; Zhao, Y.; Hu, T. Design of a large displacement thermal actuator with a cascaded V-beam amplification for MEMS safety-and-arming devices. Microsystem Technologies. 2015, 21, 2367-2374.

16. Bao, B.; Yan, N.; Geng, W. Simulation and experiment investigation on structural design and reinforcement of pyrotechnical sliding micro-actuators. Analog Integrated Circuits and Signal Processing, 2016, 88, 1-11.

17. Cochran, K.R.;Fan, L.; DeVoe, C.L. Moving reflector type micro optical switch for high-power transfer in a MEMS-based safety and arming system. Journal of Micromechanics and Microengineering. 2003, 14, $138-146$. 
18. He, G. Micro-mechanical safety mechanism based on MEMS technology theory and application. Thesis, Beijing Institute of technology, Beijing, 2006.

19. Zhou, Z.J.; Nie, W.R.; Wan, X.F. Study on Parameters of MEMS Planar Zigzag Slot for Fuze. Key Engineering Materials. 2014, 609, 813-818.

20. Feng, Y.; Hagiwara, K.; Iguchi, Y. Trench-filled Cellular Parylene Electret for Piezoelectric Transducer. Appl. Phys. Lett. 2012,100, 262901-262901.4.

21. Zhou, X.; Shan, T.; Qi, X. Analysis and design of a high power laser interrupter for MEMS based safety and arming systems. Microsystem Technologies. 2017, 23:1-10.

22. Hu, T.; Zhao, Y.; Li, X. Integration design of MEMS electro-thermal safety-and-arming devices. Microsystem Technologies. 2016, 22:1-6.

23. Li, X.; Zhao, Y.; Hu, T. Design of a large displacement thermal actuator with a cascaded V-beam amplification for MEMS safety-and-arming devices. Microsystem Technologies. 2015, 21,2367-2374.

24. Zhao, Y.L.; Hu, T.J.; Li, X.Y. Design and Characterization of a Large Displacement Electro-Thermal Actuator for a New Kind of Safety-and-Arming Device. Energy Harvesting \& Systems. 2015, 2, 143-148.

25. Jiang, B.; Qi, X.L.; Zhao, Z.N. Key Technologies Research of MEMS Pressure Sensor for Fuze. J. Applied Mechanics and Materials. 2014, 472,242-246.

26. One, K.R.; Sung, S.K.; Jae, W.B. Simplified Parametric Study on M125 Booster Mechanism and its Application for Determining the Characteristic Constant of Arming Distance. Journal of the KIMST. 2015, 18,409-414.

27. Bao, B.; Yan, N.; Geng, W. Simulation and experiment investigation on structural design and reinforcement of pyrotechnical sliding micro-actuators. Analog Integrated Circuits and Signal Processing. 2016, 88(3):1-11.

28. Liu, J.K.; Qi X.L.;Jia,J. Study on the Reliability Problem of MEMS Fuze Mechanism. Advanced Materials Research. 2012, 628, 72-77.

29. Jakob, G.; Per, D.; Helge, K. Use of conductive adhesive for MEMS interconnection in ammunition fuze applications. Journal of Micro/Nanolithography, MEMS, and MOEMS. 2010, 9, 1-10.

30. XIE, R.Z.; Ren, X.M. Research on design and firing performance of Si-based detonator. Defence Technology. 2014, 10, 34-39.

31. Wang, F.F.; Lou W.Z. The Parametric Analysis of the Lock-Releasing Mechanism in MEMS Safety and Arming Device. Key Engineering Materials. 2015,645, 986-989.

32. Wang, F.F.; Lou, W.Z.; Feng, Y. Fracture Mechanism of Movable Part in Micro-electro-mechanical Systems Device Based on Empirical Electron Theory. Micro \& Nano Letters. 2016, 11, 29-33.

33. Wang, F.F.; Lou, W.Z.; Wang, Y. Design and Analysis of a Novel Locking Mechanism of MEMS Safety and Arming Device. Key Engineering Materials. 2014,609, 856-859.

(C) 2017 by the authors. Licensee Preprints, Basel, Switzerland. This article is an open access article distributed under the terms and conditions of the Creative Commons by Attribution (CC-BY) license (http://creativecommons.org/licenses/by/4.0/). 